04

\title{
Одно- и двулучевое оптическое формирование рельефных дифракционных микроструктур в пленках карбазолсодержащего азополимера
}

\author{
(C) Н.А. Ивлиев ${ }^{1,2}$, В.В. Подлипнов ${ }^{1,2}$, С.Н. Хонина ${ }^{1,2}$, К.С. Лошманский ${ }^{3}$, А.М. Присакар ${ }^{3}$, \\ В.Г. Абашкин ${ }^{3}$, А.Ю. Мешалкин ${ }^{3}$, Е.А. Акимова ${ }^{3}$ \\ ${ }^{1}$ Институт систем обработки изображений РАН, филиал ФНИЦ „Кристаллографиия и фотоника“ РАН, \\ 4430001 Самара, Россия \\ ${ }^{2}$ Самарский национальный исследовательский университет имени академика С.П. Королёва, \\ 443086 Самара, Россия \\ ${ }^{3}$ Институт прикладной физики, \\ MD 2028 Кишинев, Молдова \\ e-mail:ivlievn@gmail.com
}

Поступила в редакцию 16.12.2020 г.

В окончательной редакции 16.12.2020 г.

Принята к публикации 23.12.2020 г.

Представлено одно- и двулучевое формирование дифракционных микроструктур в пленках карбазолсодержащего азополимера. Показана возможность записи единичных микронеровностей сфокусированным вихревым лазерным пучком с линейной и круговой поляризацией. Проведен анализ формы рельефа микроструктур от состояния поляризации. Представлен двулучевой метод создания дифракционных решеток, в котором для формирования вихревой фазы использовался пространственный модулятор света. Проведена оценка дифракционной эффективности сформированных периодических оптических структур от длительности экспозиции.

Ключевые слова: поляризационная голографическая запись, вихревой пучок, изомеризация, микрорельеф, интерферометр Маха-Цендера.

DOI: $10.21883 /$ OS.2021.04.50766.305-20

\section{Введение}

В начале 80-х годов стало возможным создание дифракционных оптических элементов (ДОЭ) с использованием моделирования, компьютерного синтеза и последующего переноса в материал цифровыми литографическими системами и в настоящее время активно развивается и применяется $[1,2]$. С использованием цифровых систем также возможно создание трехмерных оптических структур [3]. Но при этом оптическими методами с использованием двух и более интерферирующих лучей с заданными свойствами возможно существенно быстрее формировать двумерные или трехмерные дифракционные структуры, как, например, в [4-6], фотонные кристаллы были записаны на фоторезисте слабо поглощаемым излучением с использованием многолучевых методов. Поглощение фоторезиста зависит от выбранной длины волны и свойств самого фоторезиста. Еще одной степенью свободы при управлении процессами формирования оптических микроструктур может являться поляризационная чувствительность. Ранее уже исследовались результаты обработки материалов излучением с различными поляризационными состояниями [7]. В последнее время все больше растет интерес к взаимодействию поляризованного света с различными материалами $[8,9]$ В этой связи интересными с точки зрения оптических свойств являются азополимерные материалы, имеющие чувствительность к поляризации света. Одним из перспективных подходов в реализации управляемых дифракционных оптических элементов является применение азополимерных материалов, которые отличаются от других фоточувствительных полимеров обратимой трансцис-фотоизомеризацией азохромофоров, которая сопровождается молекулярной переориентацией, что позволяет динамически изменять распределение амплитуднофазового пропускания.

Взаимодействие лазерного излучения с различными веществами, содержащими азобензольные хромофоры, исследовано во множестве работ. Разработаны методы формирования трехмерных периодических массивов [10-13], двумерных поляризационных решеток $[14,15]$, а также одиночных микронеровностей [16-18]. Развитие указанных технологий дает предпосылки для реализации управляемых дифракционных оптических элементов, например, для устройств оптической памяти [19].

Созданные математические модели фотоиндуцированного массопереноса [20-23] позволяют прогнозировать форму и характеристики создаваемых микроструктур, в том числе при взаимодействии с пучками, обладающими орбитальным угловым моментом [24,25]. 


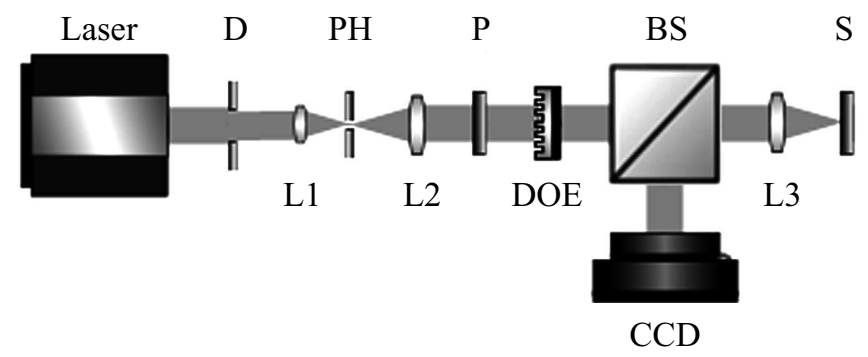

Рис. 1. Экспериментальная установка для формирования микроструктур в пленках карбазолсодержащего азополимера вихревыми пучками: D - диафрагма; L1, L2, L3 - линзы; PH - микродиафрагма (пинхол); DOE - дифракционный оптический элемент; BS - не поляризационный светоделитель; $\mathrm{CCD}$ - видеокамера; S - образец.

Нарастающий интерес к вихревым лазерным пучкам обусловлен некоторыми интересными эффектами поляризационно-фазового взаимодействия, которые проявляются только при острой фокусировке, например, усиление продольной компоненты электрического поля [26-29] или возникновение обратного потока энергии [30-33]. Однако множество полезных свойств векторных вихревых пучков имеют место и в параксиальном случае. В частности, спин-орбитальное преобразование в анизотропных кристаллах [34,35] используется для формирования цилиндрически-поляризованных пучков [36], взаимодействие вихревой фазовой сингулярности с поляризационной сингулярностью неоднороднополяризованных пучков [37] может быть использовано для детектирования поляризационного состояния пучка [38].

В настоящей работе описана одно- и двулучевая запись микроструктур вихревыми лазерными пучками с линейной и круговой поляризациями в пленке азополимера, полученного сополимеризацией органического полупроводника poly- $n$-epoxypropyl carbazole c азокрасителем Disperse Orange 3 [39]. Для формирования орбитального углового момента использовались ДОЭ и пространственный модулятор света (ПМС). Проведен теоретический анализ и экспериментальные исследования взаимодействия сформированных рельефных дифракционных структур с лазерным излучением той же длины волны.

\section{1. Однолучевая запись с использованием ДОЭ}

Однолучевая запись поверхностных структур осуществлялась с помощью одномодового лазера с линейной поляризацией с длиной волны $405 \mathrm{~nm}$. Схема экспериментальной установки, формирующая вихревой лазерный пучок и регистрирующая изображение отраженного пучка, представлена на рис. 1.

Лазерное излучение, проходя через диафрагму (D), расширяется коллиматором, состоящим из двух линз
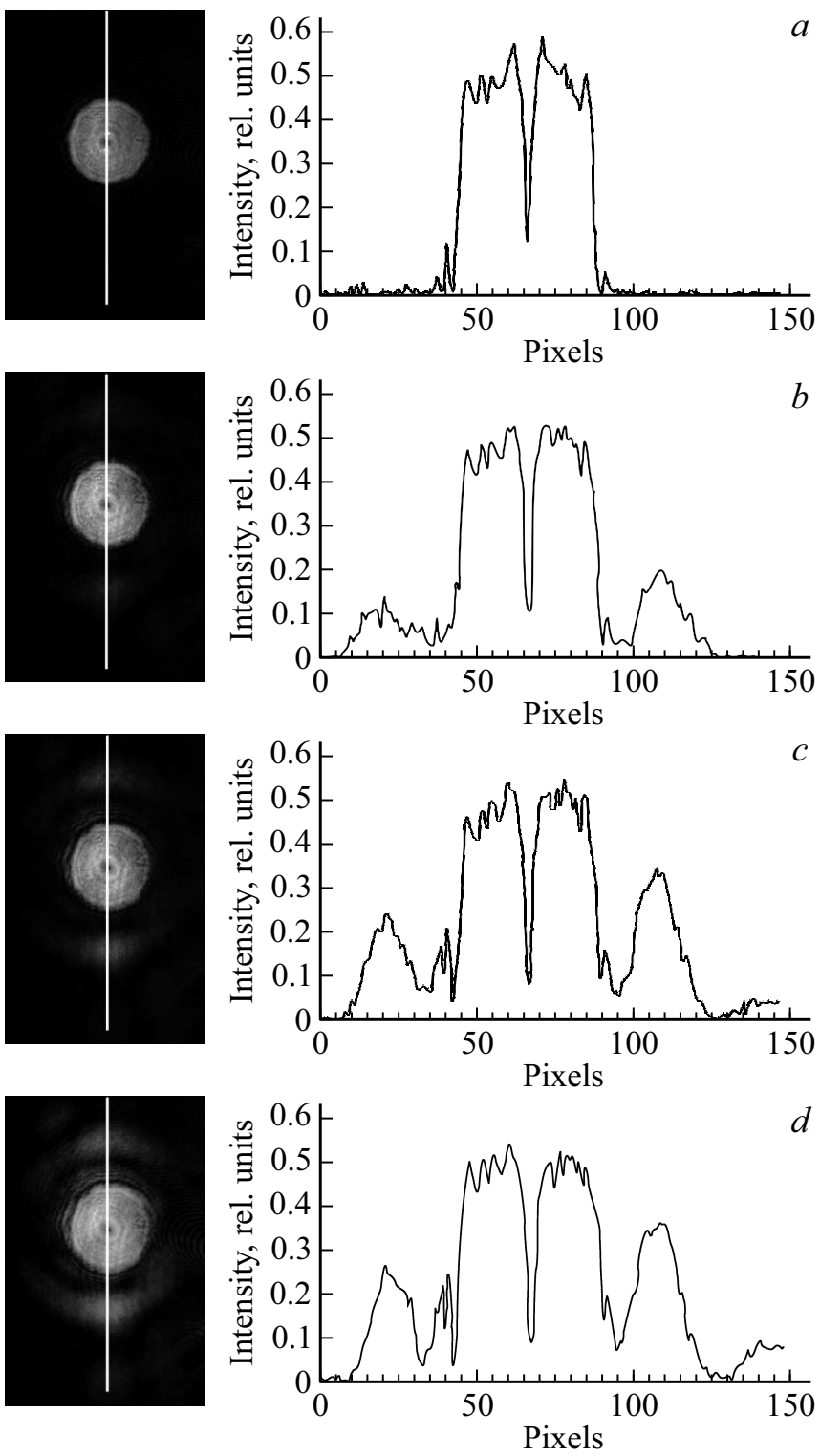

Рис. 2. Изображения отраженного вихревого пучка и соответствующие белым вертикальным линиям профили интенсивности, полученные при воздействии линейно-поляризованного пучка на пленку азополимера, для различной длительности облучения: $a-0 \mathrm{~s} ; b-15 \mathrm{~s} ; c-30 \mathrm{~s} ; d-45 \mathrm{~s}$.

(L1, L2) и пинхола (PH). Далее луч падает на дифракционный оптический элемент (DOE), который представляет собой кварцевую пластину с нанесенной амплитудной маской со структурой типа „вилка“, и фокусируется объективом (L3) с числовой апертурой 0.15 на поверхность азополимера. Четвертьволновая пластина (P) применяется для управления состоянием поляризации пучка, а контроль положения лазерного пятна, сфокусированного на образце, и регистрация отраженного пучка осуществлялся с помощью неполяризационного светоделителя (BS) и видеокамеры (CCD).

Образец с нанесенной пленкой азополимера размещался в фокусе линзы L3. Запись единичных микроне- 

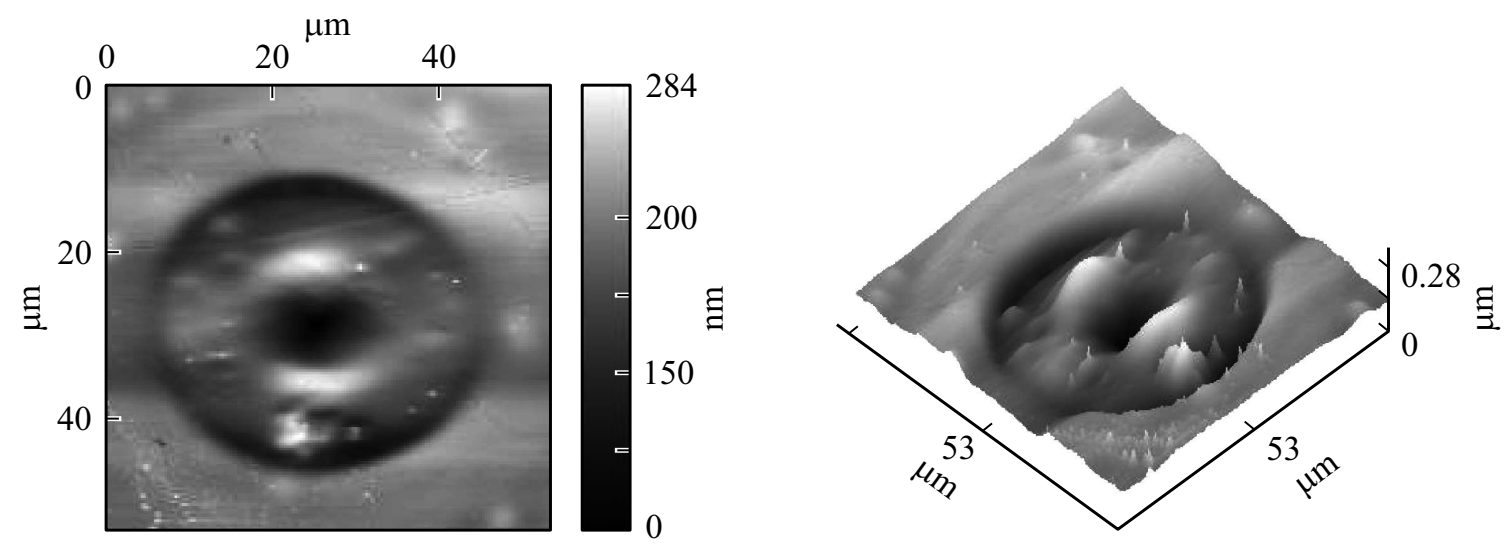

Рис. 3. Микронеровность, полученная воздействием линейно-поляризованного вихревого лазерного пучка с пленкой азополимера при времени облучения $45 \mathrm{~s}$.

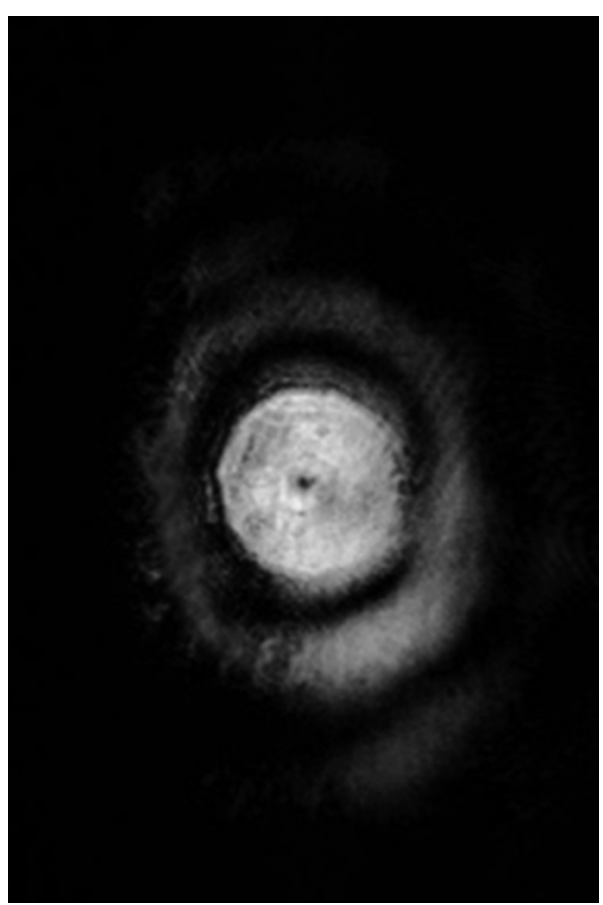

Рис. 4. Изображение отраженного вихревого пучка с круговой поляризацией, полученное при его взаимодействии с пленкой азополимера.

ровностей лазерным пучком с линейной поляризацией осуществлялся при плотности мощности $125 \mathrm{~W} / \mathrm{cm}^{2}$. Время записи изменялось в диапазоне 0-45 s. Фиксируемое видеокамерой изображение при плотности мощности пучка $30 \mathrm{~W} / \mathrm{cm}^{2}$ с интервалом $15 \mathrm{~s}$ и соответствующие профили интенсивности представлены на рис. 2.

На полученных распределениях интенсивности наблюдается незначительное уменьшение уровня центральной зоны и формирование кольцевых секторов в направлении, перпендикулярном направлению поляризации луча. С увеличением дозы излучения интенсивность кольцевых секторов увеличивается.
После окончания 45 s записи сформированный микрорельеф измерялся с помощью сканирующего зондового микроскопа Solver Pro-M, NT-MDT. Форма поверхностного микрорельефа, образованного в результате воздействия сфокусированным вихревым пучком с линейной поляризацией, показана на рис. 3 .

Сформированные структуры имеют сложную форму и симметричны относительно направления поляризации. В центре сформированной структуры наблюдается провал, соответствующий провалу интенсивности индуцирующего массоперенос вихревого пучка.

При изменении линейной поляризации на круговую тенденция увеличения интенсивности второстепенных колец от дозы излучения сохраняется, однако круговые сектора принимают форму замкнутой окружности (рис. 4).

Форма поверхностного микрорельефа, образованного в результате воздействия сфокусированного вихревого пучка с круговой поляризацией на пленку полимера, показана на рис. 5. Видно, что микронеровность приняла симметричную форму, причем её высота по сравнению с линейной поляризацией не изменилась.

Указанные особенности полученных микронеровностей выгодно отличают их от структур, сформированных взаимодействием карбазолсодержащего азополимера с гауссовыми лазерными пучками, так как такие структуры имеют очень сложную форму [8]. Симметричный отклик записанных выступов делает возможным применение представленной технологии в оптических приложениях, например в устройствах оптической памяти.

\section{2. Двулучевая поляризационная голографическая запись с помощью ПМС}

Двулучевая поляризационная голографическая запись функционирует как установка интерферометрической записи Маха-Цендера. Схема экспериментальной установки, основой которой является твердотельный лазер 

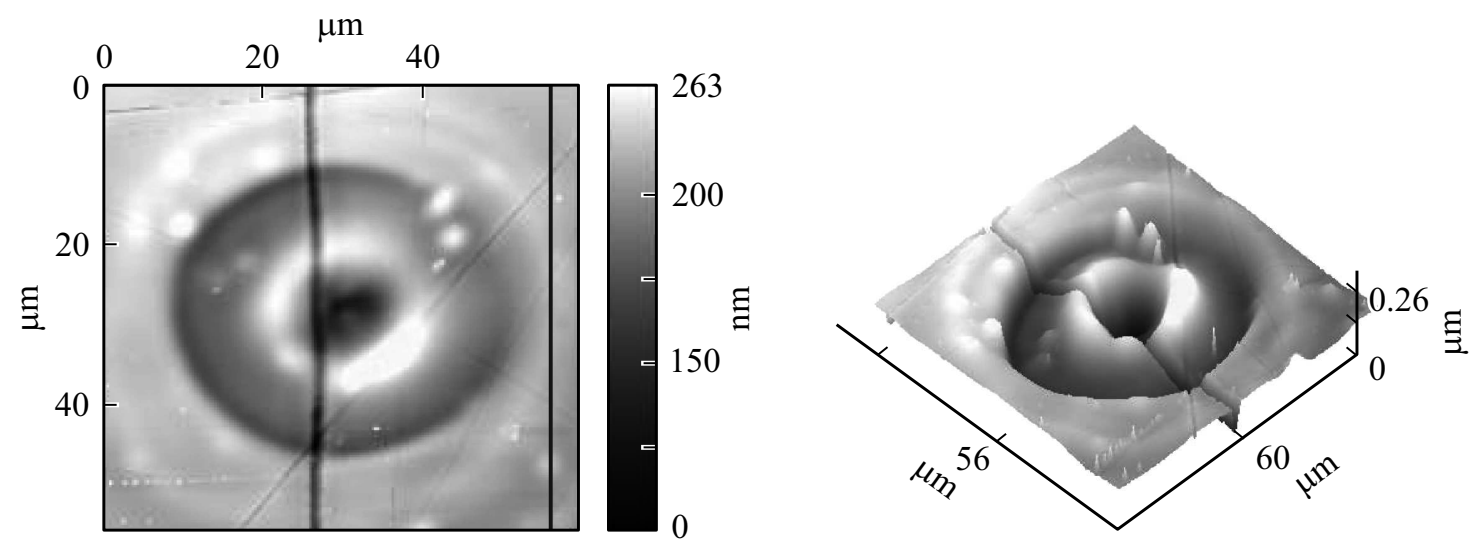

Рис. 5. Микронеровность, полученная воздействием вихревого лазерного пучка с круговой поляризацией и пленки азополимера при времени облучения $45 \mathrm{~s}$.

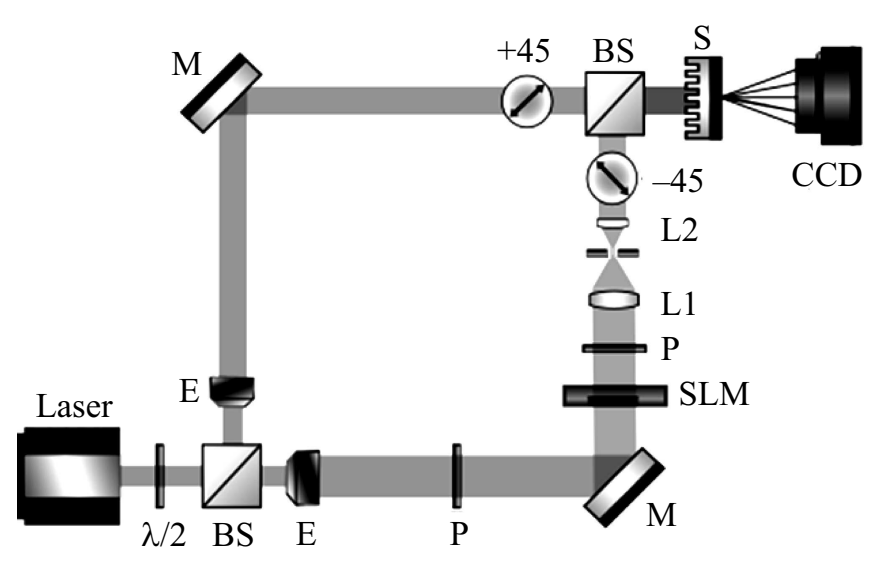

Рис. 6. Интерферометрическая установка на основе ПМС для поляризационной голографической записи: М - зеркало; $\mathrm{BS}$ - неполяризационный светоделитель, Е - расширитель; SLM - пространственный модулятор света LC-2002 с разрешением $800 \times 600$ пикселей и размером пикселя $32 \mu \mathrm{m} ; \mathrm{S}-$ образец; $\lambda / 2$ - полуволновая пластина; $\mathrm{P}-$ поляризатор; L1, L2 - линзы.

$\mathrm{TEM}_{00}$ с диодной накачкой $(\lambda=532 \mathrm{~nm}$, мощность $2 \mathrm{~W})$, показана на рис. 6.

Запись формируется при интерференции объектного пучка, проходящего через ПМС и обладающего поляризацией $-45^{\circ}$, и плоского гауссова опорного пучка, обладающего поляризацией $+45^{\circ}$ (относительно плоскости интерферирующих пучков). Таким образом, угол между направлениями поляризации интерферирующих лучей равен 90. Как было показано в исследованиях [2], кросс-поляризованные состояния световых пучков, управляемых полуволновыми пластинами, способствуют максимальной модуляции рельефа поверхности. Полуволновая пластина, размещенная непосредственно после лазера, управляет углом поляризации падающего луча относительно светоделителя. Первый светоделитель на входе интерферометра создает соотношение интенсивностей в плечах 30:70, что обеспечивает равные интенсивности выходящих интерферирующих лучей на выходе из интерферометра. Для покрытия всей матрицы ПМС пучки расширялись пространственным коллиматором. Для масштабирования голограммы, передаваемой через ПМС, в соответствии с местом записи на пленке использовалась $4 f$-телескопическая система (две линзы с разными фокусными расстояниями). Полученная дифракционная картина представлена на рис. 7.

Можно представить, что регистрируемый ДОЭ состоит из двух поверхностных решеток в направлениях $X$ и $Y$ плоскости образца. Период решетки на оси $X$ составляет $20 \mu \mathrm{m}$ и настроен на частоту полос голограммы, отображаемых на SLM. Период решетки на оси $Y$ составляет $5 \mu \mathrm{m}$ и определяется углом $\theta \approx 6.10^{\circ}$ между опорными и объектными волнами в оптической системе. Кривые на рис. 8 показывают изменение дифракционной эффективности в +11-м и +23-м порядках, измеренной в режиме реального времени, в ходе экспонирования. Максимальная эффективность в +11-м дифракционном порядке составляет около $0.1 \%$. Дифракционная эффективность в 23-м порядке при $180 \mathrm{~min}$ записи достигает максимума, равного $3.5 \%$.

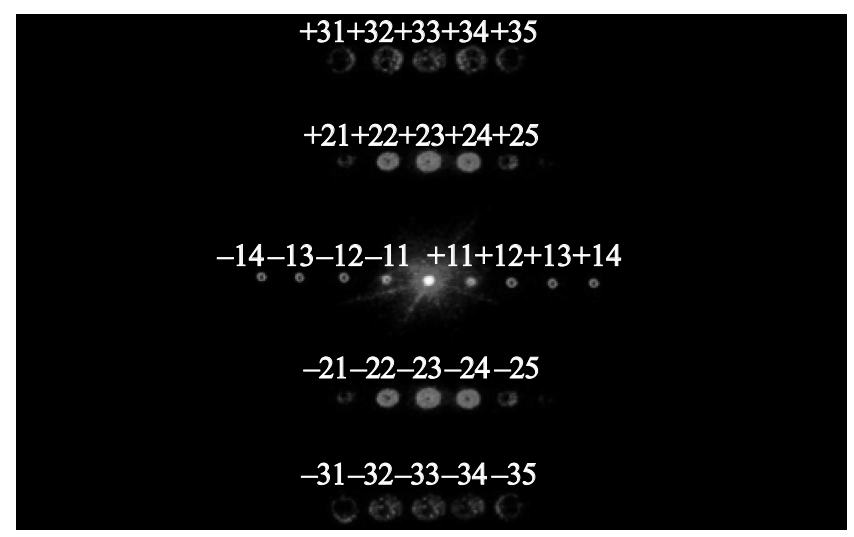

Рис. 7. Сформированная пространственная дифракционная картина. 


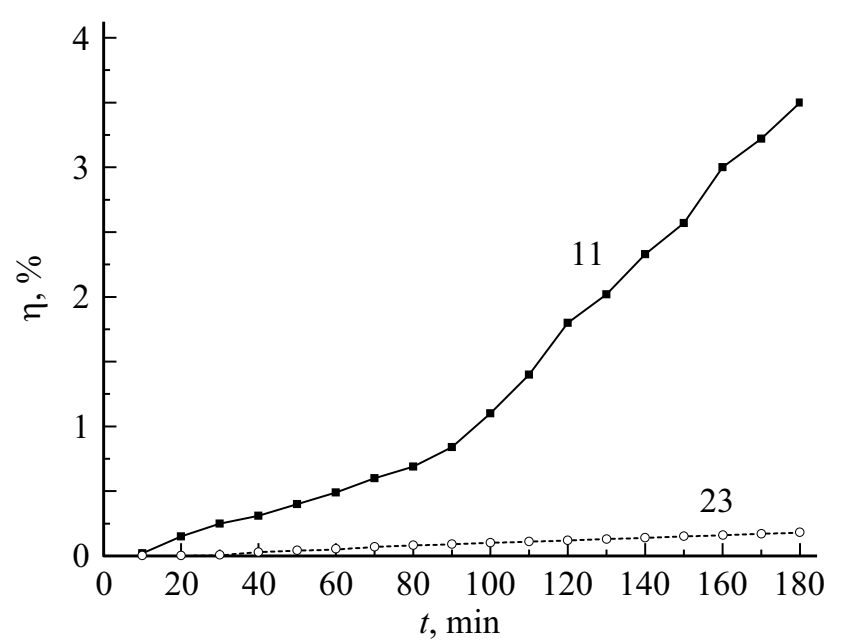

Рис. 8. Изменение дифракционной эффективности 11-го и 23-го порядков в ходе записи вихревого цифрового ДОЭ с использованием SLM.

\section{Заключение}

В работе проведены экспериментальные исследования особенностей формирования рельефных дифракционных микр оструктур пучками, обладающими орбитальным угловым моментом. Запись единичных микронеровностей осуществлялась на длине волны $405 \mathrm{~nm}$ в однолучевой схеме с применением ДОЭ для создания вихревой фазы пучка. Двулучевое формирование дифракционных решеток выполнялось на длине волны $532 \mathrm{~nm}$, а задание вихревой фазы реализовывалось с помощью ПМС.

Исследования показали, что симметричный отклик единичных микронеровностей, записанных пучками с круговой поляризацией, делает возможным их применение в оптических приложениях, например в устройствах оптической памяти. В то время как записанные дифракционные решетки позволяют формировать пучки с вихревой фазой. Дифракционная эффективность таких решеток не превышает $3.5 \%$, но повышается с увеличением высоты профиля рельефа, поэтому дальнейшие исследования будут направлены на увеличение высоты формируемого рельефа.

\section{Финансирование работы}

Данная работа была выполнена при финансовой поддержке Российского фонда фундаментальных исследований (грант № 18-07-01470) в части формирования структуры на поверхности азополимера и Национального агентства по исследованиям и разработкам Молдовы, проект № 20.80009.5007.03 в части экспериментальных исследований сформированных оптических элементов.

\section{Конфликт интересов}

Авторы заявляют, что у них нет конфликта интересов.

\section{Список литературы}

[1] Сисакян И.Н., Сойбер В.А. // Компьютерная оптика. 1987. T. 1. № 1. C. 5-18.

[2] Одиноков С.Б., Грейсух Г.И., Левин Г.Г. // Информационные технологии и нанотехнологии (ИТНТ-2020). 2020. C. 757-769.

[3] Полешук А.Г., Корольков В.П., Вейко В.П., Заколдаев Р.А., Сергеев М.М. // Автометрия. 2018. Т. 54. № 2. С. 3-19.

[4] Дьяченко П.Н., Карпеев С.В., Павельев В.С. // Компьютерная оптика. 2010. Т. 34. № 4. С. 501-505.

[5] Dyachenko P.N., Karpeev S.V., Fesik E.V., Miklyaev Y.V., Pavelyev V.S., Malchikov G.D. // Opt. Commun. 2011. V. 284. N 3. P. $885-888$.

[6] Dyachenko P.N., Karpeev S.V., Pavelyev V.S. // Opt. Commun. 2011. V. 284. N 22. P. 5381-5383.

[7] Алфёров С.В., Карпеев С.В., Хонина С.Н. // Квант. электрон. 2014. № 11. С. 1061-1065.

[8] Котляр В.В., Налимов А.Г., Ковалёв А.А., Порфирьев А.П., Стафеев С.С. // Компьютерная оптика. 2020. T. 44. № 3. С. 333-342. doi 10.18287/2412-6179-CO-686

[9] Кудрямов С.И., Данилов П.А., Порфирьев А.П., Руденко А.А., Мельник Н.Н., Кучмижак А.А., Витрик О.Б., Ионин А.А. // Письма в ЖЭТФ. 2019. Т. 110. № 11. С. 759 764.

[10] Kim D.Y., Tripathy S.K., Li L., Kumar J. // Appl. Phys. Lett. 1995. V. 66. P. 1166-1168.

[11] Meshalkin A., Robu S., Achimova E., Prisacar A., Shepel D., Abaskin V., Triduh G. // J. Optoelectron. Adv. M. 2016. V. 18. N 9-10. P. 763-768.

[12] Berberova N., Daskalova D., Strijkova V., Kostadinova D., Nazarova D., Nedelchev L., Stoykova E., Marinova V., Chi C.H., Lin S.H. // Opt. Mater. 2017. V. 64. P. 212-216.

[13] Zhou J., Yang J., Ke Y., Shen J., Zhang Q., Wang K. // Opt. Mater. 2008. V. 30. N 12. P. 1787-1795.

[14] Lagugné Labarthet F., Rochon P. // Appl. Phys. Lett. 1999. V. 75 . P. 1377.

[15] Ishitobi H., Shoji S., Hiramatsu T., Sun H.B., Sekkat Z., Kawata S. // Opt. Express. 2008. V. 16. N 18. P. $14106-$ 14114.

[16] Masuda K., Nakano S., Barada D., Kumakura M., Omatsu T. // Opt. Express. 2017. V. 25. N 11. P. 12499 12507. doi 10.1364/OE.25.012499

[17] Подлипнов В.В., Ивлиев Н.А., Хонина С.Н., Нестеренко Д.В., Васильев В.С., Акимова Е.А. // Компьютерная оптика. 2018. Т. 42. № 5. С. 779-785.

[18] Li X., Chon1 J.W.M., Evans R.A., Gu M. // Appl. Phys. Lett. 2008. V. 92. P. 063309.

[19] Sekkat Z. // Phys. Rev. E. 2020. V. 102. P. 032501.

[20] Sekkat Z. // Appl. Opt. 2016. V. 55. N 2. P. 259-268.

[21] Toshchevikov V., Ilnytskyi J., Saphiannikova M. // J. Phys. Chem. Lett. 2017. V. 8. P. 1094-1098.

[22] Yadav B., Domurath J., Kim K., Lee S., Saphiannikova M.G. // J. Phys. Chem. B. 2019. V. 123. P. 3337-3347.

[23] Ambrosio A., Marrucci L., Borbone F., Roviello A., Maddalena P. // Nat. Commun. 2012. V. 3. P. 989.

[24] Khonina S.N., Ustinov A.V., Volotovskiy S.G., Ivliev N.A., Podlipnov V.V. // Appl. Opt. 2020. V. 59. N 29. P. 9185-9194.

[25] Dorn R., Quabis S., Leuchs G. // Phys. Rev. Lett. 2003. V. 91. P. 233901.

[26] Wang H., Shi L., Lukyanchuk B., Sheppard C., Tow C. // Nature Photonics. 2008. V. 2. P. 501-505. 
[27] Khonina S.N., Alferov S.V., Karpeev S.V. // Optics Lett. 2013. V. 38. N 17. P. 3223-3226.

[28] Khonina S.N., Golub I. // Optics Lett. 2011. V. 36. N 3. P $352-$ 354.

[29] Vaveliuk P., Martinez-Matos O. // Opt. Express. 2012. V. 20. P. 26913.

[30] Mitri F.G. // J. Opt. Soc. Am. A. 2016. V. 33. P. 1661.

[31] Khonina S.N., Ustinov A.V., Degtyarev S.A. // Phys. Rev. A. 2018. V. 98. P. 043823.

[32] Khonina S. N., Ustinov A.V. // Optics Lett. 2019. V. 44. N 8. P. 2008-2011.

[33] Marrucci L., Manzo C., Paparo D. // Phys. Rev. Lett. 2006. V. 96. P. 163905.

[34] Picon A., Benseny A., Mompart J., Calvo G.F. // J. Opt. 2011. V. 13. P. 064019.

[35] Khonina S.N., Karpeev S.V., Alferov S.V., Soifer V.A. // J. Optics. 2015. V. 17. P. 065001.

[36] Moreno I., Davis J.A., Ruiz I., Cottrell D.M. // Opt. Express. 2010. V. 18. N 7. P. 7173-7183.

[37] Khonina S.N., Porfirev A.P., Karpeev S.V. // Opt. Express. 2019. V. 27. N 13. P. 18484-18492.

[38] Andries A., Abaskin V., Achimova E., Meshalkin A., Prisacar A., Sergheev S., Vlad L. // Phys. Stat. Sol. A. 2011. V. 208. N 8. P. 1837-1840.

[39] Карпеев С.В., Хонина С.Н., Харитонов С.И. // Компьютерная оптика. 2015. Т. 39. № 2. С. 211-217. 